\title{
MODELAGEM MATEMÁTICA DOS IMPACTOS EXTRAMUROS DO RUÍDO PRODUZIDO POR UMA UNIVERSIDADE EM MOSSORÓ-RN
}

\author{
C. E. M. JERÔNIMO ${ }^{1 *}$, J. A. SILVA ${ }^{1}$ e R. R. T. DA SILVA ${ }^{2}$ \\ ${ }^{1}$ Universidade Potiguar \\ ${ }^{2}$ Instituto Federal de Educação, Ciência e Tecnologia do Rio Grande do Norte \\ c_enrique@hotmail.com*
}

Artigo submetido em junho/2014 e aceito em abril/2015

DOI: $10.15628 /$ holos.2015.2197

\section{RESUMO}

Neste trabalho, desenvolveu-se um estudo para quantificação do ruído produzido por uma universidade em Mossoró-RN, bem como, estimando-se os níveis de atenuação deste ruído com distanciamento, por meio da modelagem matemática. As medições do ruído ambiental foram realizadas por meio de um analisador de Ruído no período noturno no campus da instituição, variando de 0 a $100 \mathrm{~m}$ de distância em cada vértice. Aplicaram-se os modelos matemáticos para encontrar relações entre o nível de ruído e a distância de leitura dos dados. Após análise dos resultados, encontrou-se uma relação entre a atenuação pela distância em apenas dois vértices e que os níveis de ruídos estão acima do permitido. Foi possível a determinação do parâmetro $\mathrm{K}$, para a atenuação dos níveis de ruído em dois vértices do prédio, obtendo-se valores de 5,94 e $8.44 \mathrm{~dB}(\mathrm{~A}) \cdot \mathrm{m}^{-1}$ nos vértices 3 e 4 , respectivamente. Por fim, espera-se que os resultados obtidos neste mapeamento acústico e modelagem de parâmetros matemáticos possam auxiliar no planejamento da implantação de empreendimentos e edificações futuras ao redor do campus da universidade, especialmente, pois é possível fazer a previsibilidade de certas zonas e orientar na indicação dos locais mais silenciosos e os locais mais ruidosos no seu entorno.

PALAVRAS-CHAVE: Universidade, Ruído, Atenuação.

\section{MATHEMATICAL MODELING OF IMPACTS EXTRAMURAL NOISE PRODUCED BY A UNIVERSITY IN MOSSORÓ-RN}

\begin{abstract}
In this work, we developed a study to quantify the noise produced by a university in Mossoró-RN, as well as estimating the levels of this noise attenuation with distance, by means of mathematical modeling. Environmental noise measurements were performed by means of an analyzer noise at night on the campus of the institution, ranging from 0 to $100 \mathrm{~m}$ away at each vertex. Applied mathematical models to find relations between the noise level and the reading range of the data. After analyzing the results, we found a relationship between the attenuation by distance in just two vertices and that the noise levels are higher than allowed. It was
\end{abstract}

possible to determine the parameter $\mathrm{K}$ for the attenuation of noise levels at two corners of the building, thus obtaining values of 5.94 and $8.44 \mathrm{~dB}(\mathrm{~A})$. $\mathrm{m}^{-1}$ at the vertices 3 and 4 , respectively. Finally, it is expected that the results of this acoustic mapping and modeling of mathematical parameters may assist in planning the deployment of future developments and buildings around the university campus, especially as it is possible to make the predictability of certain areas and guide the indication of local quietest and noisiest places in your surroundings.

KEYWORDS: University, Noise, Attenuation. 


\section{INTRODUÇÃO}

Segundo Rinaldi (2005), poluição sonora tem sido um dos mais notáveis impactos ambientais que assolam as cidades, na medida em que o crescimento urbano desordenado, característica típica dos países em desenvolvimento, tem trazido em seu rastro a presença sempre indesejável, nociva, e cada vez maior do ruído, ameaçando a sustentabilidade desejada.

Giannini (2013) afirma que o ser humano está de forma contínua recebendo informações sonoras. Podem-se considerar todos os sons como ruídos, mas a sua classificação é subjetiva, destacando o fato de ser ou não desejável. Segundo Ilda (1995), o ruído é uma mistura complexa de diversas vibrações, medido em uma escala logarítmica em uma unidade chamada decibel (dB).

A Conferência da Terra (ECO 92), realizada no Rio de Janeiro, em 1992, endossou a Agenda 21, um programa de ação mundial para a promoção do desenvolvimento sustentável, que envolve modificação de conceitos e práticas referentes ao desenvolvimento econômico e social. Neste contexto, o ruído foi considerado a terceira maior causa de poluição ambiental, atrás da poluição da água e do ar. Segundo o Ministério da saúde (2013), o ruído pode ser visto como o risco de agravo à saúde que atinge maior número de trabalhadores, e foi um dos elementos contemplados como alvo dessa metodologia.

Lacerda (2013) diz que nas últimas décadas, pesquisas científicas alertam para o fato de que o homem parece estar cada dia mais habituado com o ruído. Indivíduos questionados se eles sentiam-se incomodados ou molestados pelos níveis de ruído vigentes em seu ambiente laboral e/ou em seu ambiente urbano, a resposta frequente foi: “... Nós já estamos acostumados a estes ruídos, com o tempo a gente se acostuma...". Estas respostas demonstram claramente que a exposição contínua e repetida ao ruído não é mais percebida de uma maneira consciente ou incômoda, porém os autores enfatizam que os efeitos desta exposição continuam a atuar danosamente contra a saúde destes indivíduos.

Segundo Araújo (2007), o ruído é um poluente invisível, o qual lentamente vai agredindo os indivíduos, causando-Ihes danos tanto auditivos, psíquicos e em todo o organismo. Vários estudos têm mostrado a relação direta existente entre poluição sonora e distúrbios da saúde do cidadão urbano. Os principais estão relacionados aos distúrbios do sono, de forma direta ou indiretamente ao ruído, através de estresse ou perturbação do ritmo biológico.

Em nosso dia-a-dia, é facilmente detectável a presença do ruído. Ele se faz presente desde a conversação até nos mais robustos processos da construção de grandes prédios, mas sua definição não é fácil, pois pode ser interpretada de forma fisiológica ou psicológica. De acordo com o manual do ruído (2001), "ruído é um som ou conjunto de sons desagradáveis e/ou perigosos, capazes de alterar o bem estar fisiológico ou psicológico das pessoas, de provocar lesões auditivas que podem levar à surdez e de prejudicar a qualidade e quantidade do trabalho".

De acordo com Silva (2009), para as pessoas certos sons são agradáveis e quando são percebidos como perturbadores e incômodos são definidos como ruído. Ou seja, para muitos, o som quando não concorda com os interesses momentâneos de um indivíduo este é considerado um incômodo. 
Zannin (2013) demonstra que pela ótica física, o ruído é uma mistura de vibrações, medidas em uma escala logarítmica. Acima do limiar da percepção dolorosa pode produzir danos ao aparelho auditivo. A unidade de medida da intensidade do som é o Decibel (dB), em que se considera a unidade $(1 \mathrm{~dB})$ como o valor correspondente ao som mais baixo que o ouvido humano consegue detectar. Por esse fato, $10 \mathrm{~dB}$ correspondem a um som 10 vezes mais intenso que $1 \mathrm{~dB}, 20 \mathrm{~dB} 100$ vezes mais intenso, $30 \mathrm{~dB} 1000$ vezes e assim sucessivamente. Segundo Barros (2000), a capacidade de causar danos à audição não depende somente do seu nível, mas depende também do tempo de duração. Uma exposição de um minuto a $100 \mathrm{~dB}(\mathrm{~A})$ não é tão prejudicial quanto uma de 60 minutos a $90 \mathrm{~dB}(\mathrm{~A})$.

De acordo com o Ministério do trabalho (2001), as manifestações mais importantes encontradas em seres humanos expostos ao ruído são: alteração da qualidade do sono; alteração da percepção e da compreensão de fala; modificação da frequência cardíaca acompanhada de sudorese; diminuição da capacidade de desempenho de tarefas psicomotoras; reação muscular; contração do abdômen e do estômago; alteração da função intestinal; lesões teciduais dos rins e do fígado; aumento da produção de hormônios da tireoide e da produção de adrenalina; aumento da produção de corticotrofina; queda da resistência a doenças infecciosas; disfunção no sistema reprodutor; contração dos vasos sanguíneos; dilatação das pupilas; irritabilidade; ansiedade e insônia.

Os níveis de ruído encontrados em tráfego de veículos, em alguns lugares, costumam estar acima dos níveis considerados responsáveis pelas perdas auditivas. O som excessivo provocado pelo trânsito, pelas indústrias, pelas áreas de recreação, por pessoas conversando, por aviões, por exemplo, é o maior responsável pela poluição sonora.

Silva (2009) diz que a poluição sonora e sua consequente influência sobre o meio ambiente e sobre a qualidade de vida dos seres humanos têm sido alvo de várias pesquisas em diversas partes do mundo. Zannin (2013) aponta que o número de reclamações por parte da população devido ao incômodo gerado pelo ruído tem aumentado com o passar dos anos, o que demonstra uma tendência de crescimento deste problema.

Um levantamento feito nos Estados Unidos, segundo Barros (2000), mostrou que $46 \%$ das pessoas entrevistadas manifestaram-se incomodadas pelo ruído urbano, sendo que $86 \%$ destes apontaram o ruído de trafego como a maior causa do incômodo. Lacerda (2013) mostra que uma pesquisa semelhante realizada na cidade de Londres apontou também o ruído de trafego rodoviário como sendo a maior causa de incômodo para as pessoas localizadas tanto nas suas residências, nas ruas, como no trabalho.

A Fonoaudiologia, enquanto ciência investiga os danos ocasionados pelo ruído à saúde auditiva da população e também os seus efeitos na comunicação humana. Um processo comunicativo eficiente exige que a mensagem seja compreendida, e quando existe falha nessa recepção, estamos diante de possíveis alterações de linguagem e do processamento da informação sonora. Essa comunicação é uma atividade inerente ao ser humano, que dela utiliza para expressar seu pensamento, seus sentimentos e opiniões. É por meio da comunicação que o homem consegue viver em sociedade, compartilhando ideias, crenças e valores. De acordo com Nascimento (2013), a comunicação exerce papel fundamental em qualquer organização e, principalmente, em uma instituição de ensino superior, cuja função básica é comunicar para 
formar cidadãos e profissionais, incluindo todo o ciclo de capacitação e aprendizado, que todo ele é feito praticamente utilizando a linguagem falada.

Fé (2009) mostra que com o objetivo de tentar reduzir os problemas gerados por níveis excessivos de ruído, legislações nacionais e internacionais têm estabelecido limites sonoros para diversas atividades de modo a garantir a segurança e o conforto da comunidade. O objetivo do estabelecimento de padrões de qualidade ambiental consiste em prevenir ou corrigir os inconvenientes e prejuízos da poluição do meio ambiente.

Segundo Nagem (2004), na época atual, caracterizada pelo surgimento de um novo paradigma de planejamento, que é voltado para o desenvolvimento sustentável e para uma enorme mudança política, social e tecnológica, a poluição sonora nas cidades constitui um problema que tende a se disseminar de uma forma incontrolada. Assim, é importante criar estratégias efetivas de planejamento global que levem em conta as questões ambientais na expansão urbana e, em particular, o controle das fontes de ruído, que se constituem como as causas principais do aumento da poluição sonora. Visto que apesar da existência de normas nacionais e internacionais relacionadas à medição sonora, não há uma metodologia especifica para o mapeamento do ruído ambiental e nem um fiel cumprimento desses elementos na escala dos impactos ao meio ambiente, tendo um foco na saúde ocupacional de quem está exposto a tais cenários. Logo, cada pesquisador utiliza, assim, uma metodologia própria tendo-se, como resultado, uma diversidade de parâmetros e de procedimentos para a coleta de dados e para o mapeamento sonoro.

Diante desse quadro, neste trabalho tem-se como objetivo a quantificação dos níveis de ruídos produzidos por uma instituição de ensino localizada na cidade de Mossoró, onde transitam mais de 5.000 pessoas diariamente.

\section{MODELAGEM MATEMÁTICA DA PROPAGAÇÃO DO RUÍDO}

De acordo com Saliba (2011), matematicamente o nível de pressão sonora é o que determina a intensidade do som e representa a relação do logaritmo entre a variação da pressão (P) provocada pela vibração e a pressão que atinge o limiar da audibilidade. Por meio de pesquisas realizadas com pessoas jovens, previamente sem problemas auditivos, foi revelado que o limiar de audibilidade é de $2 \times 10^{-5} \mathrm{~N} . \mathrm{m}^{-2}$ ou $0,00002 \mathrm{~N} \cdot \mathrm{m}^{-2}$. Assim, convencionou-se este valor como sendo 0 (zero) dB, ou seja, o nível de pressão de referência utilizado pelos fabricantes dos medidores de nível de pressão sonora. Quando uma pessoa fica exposta a uma pressão sonora de $200 \mathrm{~N} . \mathrm{m}^{-2}$, ela começa a sentir dor no ouvido, sendo assim, este limite é denominado como limiar da dor, correspondendo a $140 \mathrm{~dB}$. A determinação do nível de pressão sonora é feita através de uma relação logarítmica, conforme a Equação 1.

$$
N P S=20 \log \left(\frac{P}{P_{0}}\right)
$$

Onde:

$\mathrm{P}=$ raiz média quadrática (RMS) das variações dos valores instantâneos da pressão sonora;

PO = Pressão de referência que corresponde ao limiar da audibilidade $\left(2 \times 10^{-5} \mathrm{~N} \cdot \mathrm{m}^{-2}\right)$.

Conforme o explicitado em Saliba (2011), o nível de intensidade sonora, também expresso em $\mathrm{dB}$, é igual a NIS = log $10(\mathrm{I} / \mathrm{IO})$, onde I é a intensidade sonora de um ponto específico e a 
quantidade média de energia sonora transmitida através de uma unidade de área perpendicular à direção da propagação do som. O nível de intensidade sonora expresso em dB é igual a:

$$
N P S=10 \log \left(\frac{l}{l_{0}}\right)
$$

Onde:

I = Potência sonora da fonte em Watts e representa a quantidade de energia acústica produzida por uma fonte sonora por unidade de tempo.

10 = Potência sonora de referência igual a 10-12 Watts.

Como mostrado por Andrade (2004), no tocante a atenuação do ruído diversos são os fatores ambientais que influenciam a propagação e impedância sonora através da atmosfera: distância, solo, vegetação, direção e intensidade dos ventos, fachadas, temperatura, umidade relativa do ar e, ainda, a presença de partículas em suspensão (poluição). As influências só são significativas para grandes distâncias, onde o nível sonoro sofre uma redução de $6 \mathrm{~dB}(\mathrm{~A})$ para fontes pontuais, cada vez que a distância entre a fonte e o receptor é dobrada. Para uma fonte linear, a redução é da ordem de $3 \mathrm{~dB}(\mathrm{~A}) / \mathrm{dd}$ (cada vez que a distância é dobrada).Como já mencionado, obras de construções de edifícios e outras atividades produtoras de ruído podem ser a grandes distâncias, consideradas fontes pontuais fixas; obras de pavimentação devem ser tratadas como fontes lineares de grandes dimensões.

Para ambientes fechados, ou abertos em planos de fontes pontuais sobre um plano refletido, a atenuação natural do ruído pode ser descrita conforme a Equação (3).

$$
N P S=N W S+10 \log \left(\frac{S}{R}\right)+10 \log \left(\frac{Q}{2 \pi r^{2}}\right)+S R I f
$$

Onde:

$$
\begin{aligned}
& \begin{array}{l}
R=\left(\frac{S x \bar{\alpha}}{1-\bar{\alpha}}\right) \quad \text { (Constante da sala que caracteriza a reverbe } \\
\quad \bar{\alpha}=\frac{\sum \alpha_{i} x S_{i}}{\sum S_{i}} \quad \text { (coeficiente de absorção médio); }
\end{array} \\
& \text { Sendo } \begin{array}{l}
\text { ai = coeficiente de absorção interno parcial; } \\
\text { S = área total da superfície interna, em m2; }
\end{array} \\
& \text { Si = área interna parcial, em m2; } \\
& \text { SRIf = índice de atenuação acústica das paredes na fonte. }
\end{aligned}
$$

Ademais, para a transmissão do som pelas aberturas, no caso de uma obra semi-aberta cuja propagação atinge um receptor externo na divisa de uma edificação ou interno por aberturas, pode-se aplicar a fórmula dos dois itens precedentes, com $R=0$ para todas as freqüências. Esta é válida igualmente para as pequenas aberturas desde que suas dimensões sejam superiores à espessura da parede. Sendo assim, a equação (3) pode ser simplificada, com a concatenação do termo para uma relação constante, bem como, uma reformulação dos elementos para Q, NWS e SRIf, agrupando-se numa única constante K. Dessa forma, obtém a Equação na forma da expressão (4), a seguir: 


$$
\begin{aligned}
& N P S=A+K \log (r), \text { Onde }: \\
& A=N W S+10 \log \left(\frac{S}{R}\right)+S R I f \\
& K=-20\left(\frac{Q}{2 \pi}\right)
\end{aligned}
$$

Andrade (2004) diz que, considerando o modelo exposto é possível avaliar o comportamento da atenuação natural do ruído com a distância, através da parametrização das constantes A e K. Entretanto, o ruído urbano, genericamente, é provocado por fontes móveis e fixas, cuja propagação percorre o espaço urbano e é percebido sob a forma de ruído de fundo e sob a forma de campo direto. As fontes urbanas consideradas significativas são provenientes das indústrias (incluindo a construção civil) do comércio, dos veículos (terrestres e aéreos), do lazer e das habitações, sendo as mais habituais: tráfego, motores, escapamentos, sirenes, pavimentação das ruas, marteletes, buzinas, diversão pública em áreas residenciais (bares, boates, discotecas, restaurantes com música ao vivo e instalações sem tratamento acústico), comércio local, carros de som amplificado, equipamentos sonoros, brinquedos, academias de ginástica, templos religiosos etc. As máquinas fixas da construção civil (pontuais) e móveis representam o campo sonoro de uma fonte de dimensão finita situada a grande distância, como é o caso do elemento deste estudo. Uma fonte qualquer pode ser representada por uma superposição de diversas fontes fixas e móveis, logo a modelagem se torna mais completa e complexa quando determinadas as potências acústicas das regiões estudadas, porém, neste estudo não serão objeto desta correção.

\section{MATERIAIS E MÉTODOS}

\subsection{Caracterização da Pesquisa}

O estudo, conforme classificação dada por Silva; Menezes (2005), constitui-se de uma Pesquisa Aplicada, visto que "objetiva gerar conhecimentos para aplicação prática e dirigidos à solução de problemas específicos". Do ponto de vista da forma de abordagem do problema é uma Pesquisa Quantitativa: "considera que tudo pode ser quantificável, o que significa traduzir em números opiniões e in-formações para classificá-las e analisá-las. Requer o uso de recursos e de técnicas estatísticas (percentagem, média, moda, mediana, desvio-padrão, coeficiente de correlação, análise de regressão, etc.)". Do ponto de vista de seus objetivos é uma Pesquisa Exploratória: "visa proporcionar maior familiaridade com o problema com vistas a torná-lo explícito ou a construir hipóteses. Envolve levantamento bibliográfico; entrevistas com pessoas que tiveram experiências práticas com o problema pesquisado; análise de exemplos que estimulem a compreensão. Assume, em geral, as formas de Pesquisas Bibliográficas e Estudos de Caso". Em relação ao enquadramento técnico é vista como uma Pesquisa Experimental: "quando se determina um objeto de estudo, selecionam-se as variáveis que seriam capazes de influenciálo, definem-se as formas de controle e de observação dos efeitos que a variável produz no objeto".

A hipótese pauta-se na possibilidade de haver uma relação matemática entre a distância e a atenuação natural do ruído, cuja constante de proporcionalidade se ajusta a um modelo 
logarítmico, cuja constante é obtida através da regressão linear pelo método de mínimos quadrados.

A estrutura da pesquisa consiste em:

- Realização do levantamento teórico, que orienta a caracterização do objeto de estudo, as definições e conceitos a serem utilizados em análise e correntes de pensamentos que norteiam a hipótese da pesquisa;

- Levantamento de dados em campo, por meio de incursões investigativas no campus de uma Universidade em Mossoró-RN;

- Estudo sobre o cumprimento dos requisitos atribuídos pelas Normas Regulamentadoras do Ministério do Trabalho e Emprego (MTE), instruções normativas do Ministério do Meio Ambiente e resoluções do CONAMA;

- Realização de uma análise estatística dos dados obtidos e desdobramento dos dados a serem ajustados na modelagem matemática.

Os dados coletados em campos foram organizados, de acordo com a necessidade da utilização em pesquisa, e utilizados para elaboração do levantamento da parametrização para modelagem matemática e regressão linear dos modelos desenvolvidos. Os dados experimentais foram tratados estatisticamente e ajustados aos modelos lineares por meio do método de mínimos quadrados, com obtenção de parâmetros médios, desvios padrões e coeficientes de determinação $\left(R^{2}\right)$.

\subsection{Espaço Amostral}

As medições foram realizadas em Mossoró-RN no campus da Universidade, Figura 1. 0 monitoramento foi realizado em diferentes distâncias das fontes de medição, para correlação futura entre a atenuação e o espaçamento físico. As leituras foram realizadas em 6 replicadas para os pontos monitorados. Um esquemático dos pontos monitorados é apresentado na Figura 2.

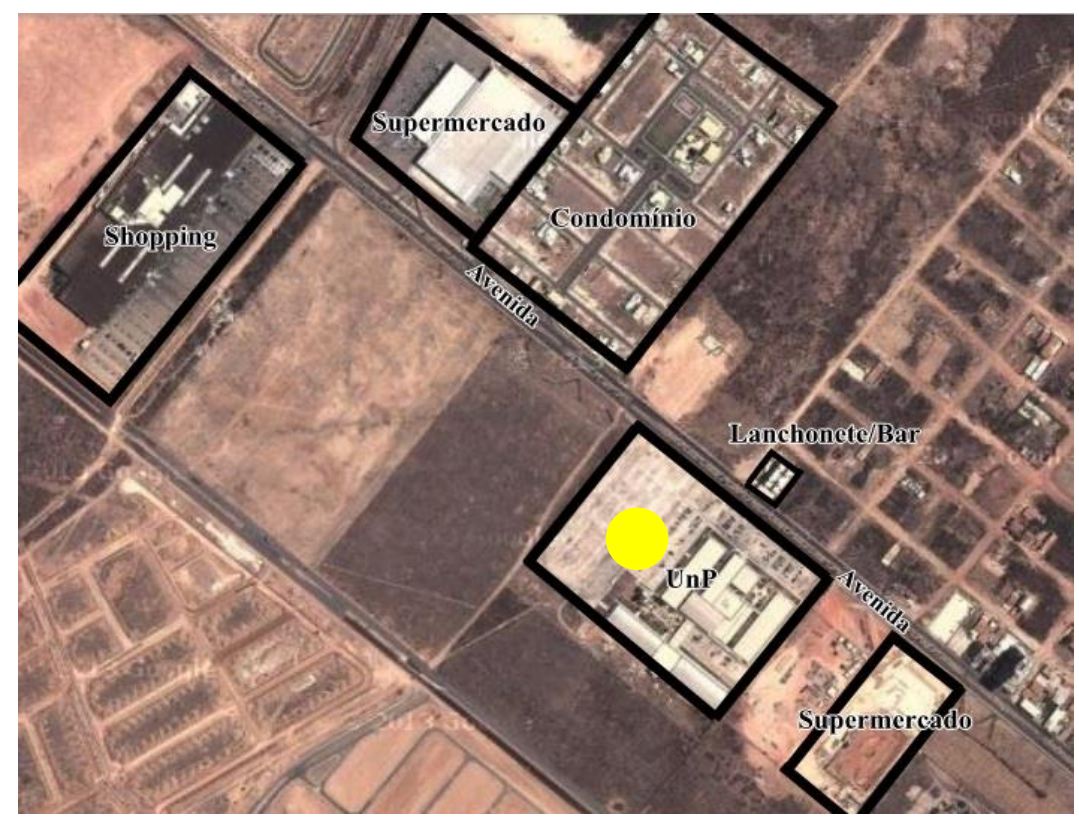


Figura 1: Local de coleta dos dados Universidade, campus Mossoró-RN. Fonte: Google Earth.

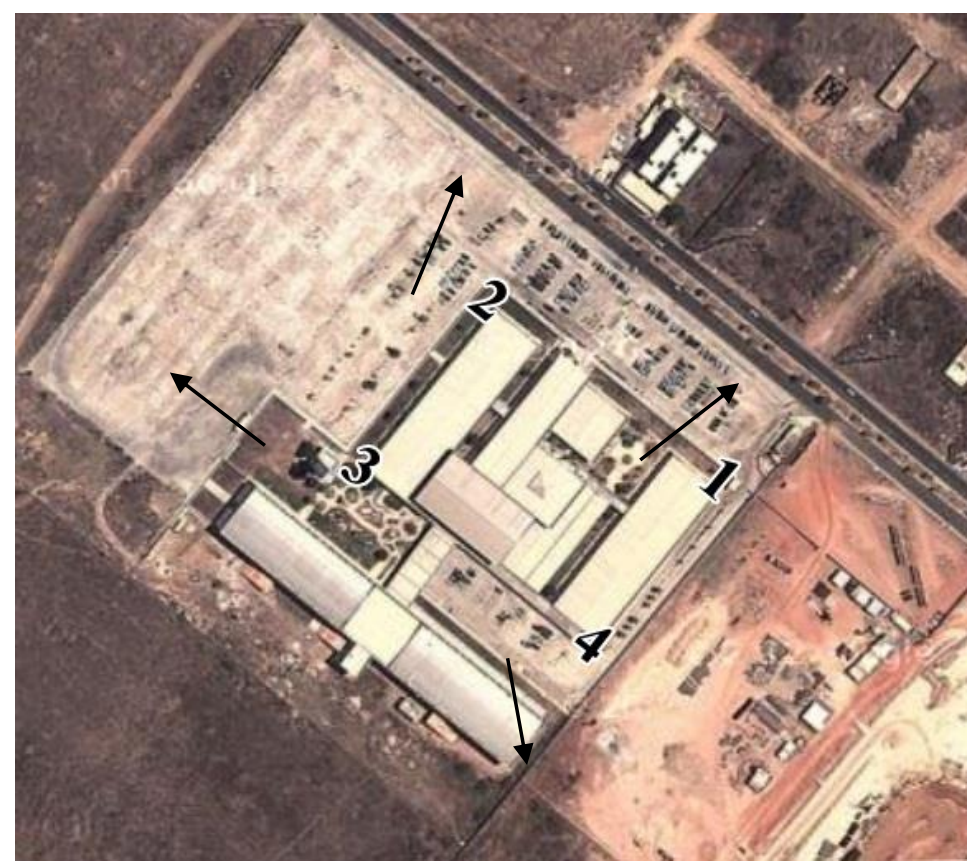

Figura 2: Vértices e direções da coleta dos dados da Universidade, campus Mossoró-RN. Fonte: Google Earth.

\subsection{Equipamentos}

A coleta dos dados foi realizada com um analisador de Ruído modelo 2260 (Brüel \& Kjaer, Dinamarca), equipamento em conformidade com as normas da ABNT (2013), configurado da seguinte forma: tempo de resposta rápido (Fast), medindo em decibel o nível de pressão sonora (NPS) e usando a ponderação em frequência $A d B(A)$. A faixa de medição compreendeu de 40 a $120 \mathrm{~dB}(\mathrm{~A})$ e o espectro sonoro em bandas de oitava de $31,5 \mathrm{~Hz}$ a $8 \mathrm{kHz}$.

\subsection{Procedimento de Coleta dos dados}

As medições do ruído ambiental foram realizadas em junho de 2013 , no período noturno entre as $20 \mathrm{~h} 00 \mathrm{~m}$ e $21 \mathrm{~h} 30 \mathrm{~m}$. Em cada período de análise, realizou-se um conjunto de 8 medições com 6 leituras para cada distância dos vértices, variando de 0 a $100 \mathrm{~m}$ em cada vértice. As medições pontuais foram realizadas em intervalos de poucos minutos. O equipamento foi sempre colocado a 1,5 metros de altura do solo, na altura da mão do responsável pela coleta. Os dados eram registrados em planilha manual, sendo posteriormente tabulados e compilados os dados em planilha eletrônica, ambiente Excel $^{\circledR}$.

\section{RESULTADOS E DISCUSSÃO}

Considerando a série de dados obtidos pode-se observar que os valores das leituras de ruído foram entre 50,2 dB (para o vértice de menor exposição) a 65,4 dB (para o vértice de maior exposição) na distância 0 (zero), ou seja, no muro da instituição. Os dados obtidos nas campanhas de monitoramento encontram-se nas Tabelas 1 a 4. 
Tabela 1: Dados da Média (M), Mediana (Me), Desvio Padrão Populacional (DP), Desvio padrão Amostral (DA), Variância Populacional (VP) e Variância Amostral (VA), para o Vértice 1.

\begin{tabular}{ccccccc}
\hline & \multicolumn{3}{c}{ Vértice $\mathbf{1}$} & & & \\
\cline { 2 - 7 } Distância da leitura (m) & $\mathbf{M}$ & Me & DP & DA & VP & VA \\
\hline 0-no muro & 60,2 & 60,2 & 0,7 & 0,8 & 0,7 & 0,5 \\
$\mathbf{1}$ & 60,5 & 60,5 & 0,1 & 0,1 & 0,0 & 0,0 \\
$\mathbf{2}$ & 62,3 & 62,2 & 0,8 & 1,0 & 1,0 & 0,7 \\
$\mathbf{3}$ & 62,9 & 62,9 & 0,8 & 1,0 & 1,0 & 0,7 \\
$\mathbf{5}$ & 63,8 & 63,7 & 0,9 & 1,1 & 1,1 & 0,7 \\
$\mathbf{1 0}$ & 65,5 & 65,3 & 0,8 & 1,0 & 1,0 & 0,7 \\
$\mathbf{5 0}$ & 71,7 & 71,9 & 2,1 & 2,6 & 6,6, & 4,4 \\
$\mathbf{1 0 0}$ & 66,7 & 67,9 & 3,1 & 3,8 & 14,4 & 9,6 \\
\hline
\end{tabular}

Tabela 2: Dados da Média (M), Mediana (Me), Desvio Padrão Populacional (DP), Desvio padrão Amostral (DA), Variância Populacional (VP) e Variância Amostral (VA), para o Vértice 2.

\begin{tabular}{ccccccc}
\hline & \multicolumn{3}{c}{ Vértice $\mathbf{2}$} & & & \\
\cline { 2 - 6 } Distância da leitura (m) & $\mathbf{M}$ & Me & DP & DA & VP & VA \\
\hline 0- no muro & 65,4 & 65,3 & 0,9 & 1,2 & 1,3 & 0,9 \\
$\mathbf{1}$ & 66,8 & 66,6 & 0,9 & 1,1 & 1,3 & 0,9 \\
$\mathbf{2}$ & 68,3 & 68,1 & 1,0 & 1,2 & 1,4 & 0,9 \\
$\mathbf{3}$ & 72,0 & 71,9 & 1,0 & 1,2 & 1,4 & 1,0 \\
$\mathbf{5}$ & 73,6 & 73,6 & 0,6 & 0,8 & 0,6 & 0,4 \\
$\mathbf{1 0}$ & 75,2 & 75,3 & 1,1 & 1,3 & 1,7 & 1,1 \\
$\mathbf{5 0}$ & 93,5 & 93,5 & 1,7 & 2,1 & 4,2 & 2,8 \\
$\mathbf{1 0 0}$ & 104,6 & 103,6 & 1,8 & 2,1 & 4,6 & 3,1 \\
\hline
\end{tabular}

Tabela 3: Dados da Média (M), Mediana (Me), Desvio Padrão Populacional (DP), Desvio padrão Amostral (DA), Variância Populacional (VP) e Variância Amostral (VA), para o Vértice 3.

\begin{tabular}{ccccccc}
\hline & \multicolumn{3}{c}{ Vértice 3 } & & & \\
\cline { 2 - 6 } Distância da leitura (m) & $\mathbf{M}$ & Me & DP & DA & VP & VA \\
\hline 0-no muro & 56,5 & 56,5 & 2,5 & 3,1 & 9,6 & 6,4 \\
$\mathbf{1}$ & 53,6 & 53,5 & 1,2 & 1,5 & 2,3 & 1,5 \\
$\mathbf{2}$ & 50,7 & 50,6 & 1,5 & 1,9 & 3,5 & 2,4 \\
$\mathbf{3}$ & 45,6 & 46,1 & 1,5 & 1,9 & 3,6 & 2,4 \\
$\mathbf{5}$ & 42,8 & 43,3 & 1,4 & 1,7 & 2,8 & 1,8 \\
$\mathbf{1 0}$ & 38,4 & 39,3 & 2,6 & 3,1 & 9,9 & 6,6 \\
$\mathbf{5 0}$ & 35,6 & 36,0 & 1,5 & 1,8 & 3,4 & 2,2 \\
$\mathbf{1 0 0}$ & 34,3 & 34,4 & 0,5 & 0,7 & 0,5 & 0,3 \\
\hline
\end{tabular}

Tabela 4: Dados da Média (M), Mediana (Me), Desvio Padrão Populacional (DP), Desvio padrão Amostral (DA), Variância Populacional (VP) e Variância Amostral (VA), para o Vértice 4.

\begin{tabular}{ccccccc}
\hline & \multicolumn{3}{c}{ Vértice $\mathbf{4}$} & & & \\
\cline { 2 - 6 } Distância da leitura (m) & $\mathbf{M}$ & Me & DP & DA & VP & VA \\
\hline 0- no muro & 50,2 & 50,5 & 0,4 & 0,5 & 0,2 & 0,2 \\
$\mathbf{1}$ & 49,5 & 49,0 & 1,2 & 1,5 & 2,2 & 1,4 \\
$\mathbf{2}$ & 46,1 & 46,7 & 1,4 & 1,7 & 2,9 & 1,9 \\
$\mathbf{3}$ & 45,1 & 44,8 & 0,8 & 1,0 & 1,0 & 0,7 \\
$\mathbf{5}$ & 44,1 & 43,5 & 1,0 & 1,2 & 1,5 & 1,0 \\
$\mathbf{1 0}$ & 39,7 & 39,9 & 1,0 & 1,3 & 1,6 & 1,1 \\
$\mathbf{5 0}$ & 37,6 & 37,4 & 0,4 & 0,5 & 0,3 & 0,2 \\
\hline
\end{tabular}


Observando-se os dados obtidos é possível identificar que as médias dos níveis de ruído apresentam-se superiores aos recomendados pela NBR 10151, que estabelece o padrão de $45 \mathrm{~dB}$ (A) para o horário noturno (Tabela 5). Estes resultados são semelhantes aos resultados obtidos por SILVA $(2009)^{8}$, que mostram níveis de ruído na porta de escolas variando de 68 a $75 \mathrm{~dB}$, acima do especificado pela NBR 10151 que indica $50 \mathrm{~dB}(\mathrm{~A})$ durante o dia.

Tabela 5: Nível de critério de avaliação NCA para ambientes externos, em dB (A).

\begin{tabular}{lcc}
\hline \multicolumn{1}{c}{ Tipos de áreas } & Diurno & Noturno \\
\hline Áreas de sítios e fazendas & 40 & 35 \\
Áreas estritamente residencial urbana ou de hospitais ou de escolas & 50 & 45 \\
Área mista, predominantemente residencial & 55 & 50 \\
Área mista, com vocação comercial e administrativa & 60 & 55 \\
Área mista, com vocação recreacional & 65 & 55 \\
Área predominantemente industrial & 70 & 60 \\
\hline
\end{tabular}

Fonte: NBR 10151.

Para as condições da modelagem da curva de atenuação da influência do meio, como uma forma de visualização do decaimento de uma determinada fonte de ruído em função da distância, percorrida num determinado local, foram ajustados os modelos linearizados para a Equação (4), a fim de analisar sua aderência a tal comportamento, bem como, a determinação dos parâmetros A e K. Nesse cenário na Figura 3 são apresentadas as curvas obtidas com as médias das leituras dos quatro vértices da Universidade, com auxílio de linhas de tendência para um ajuste linear por meio do método dos mínimos quadrados.

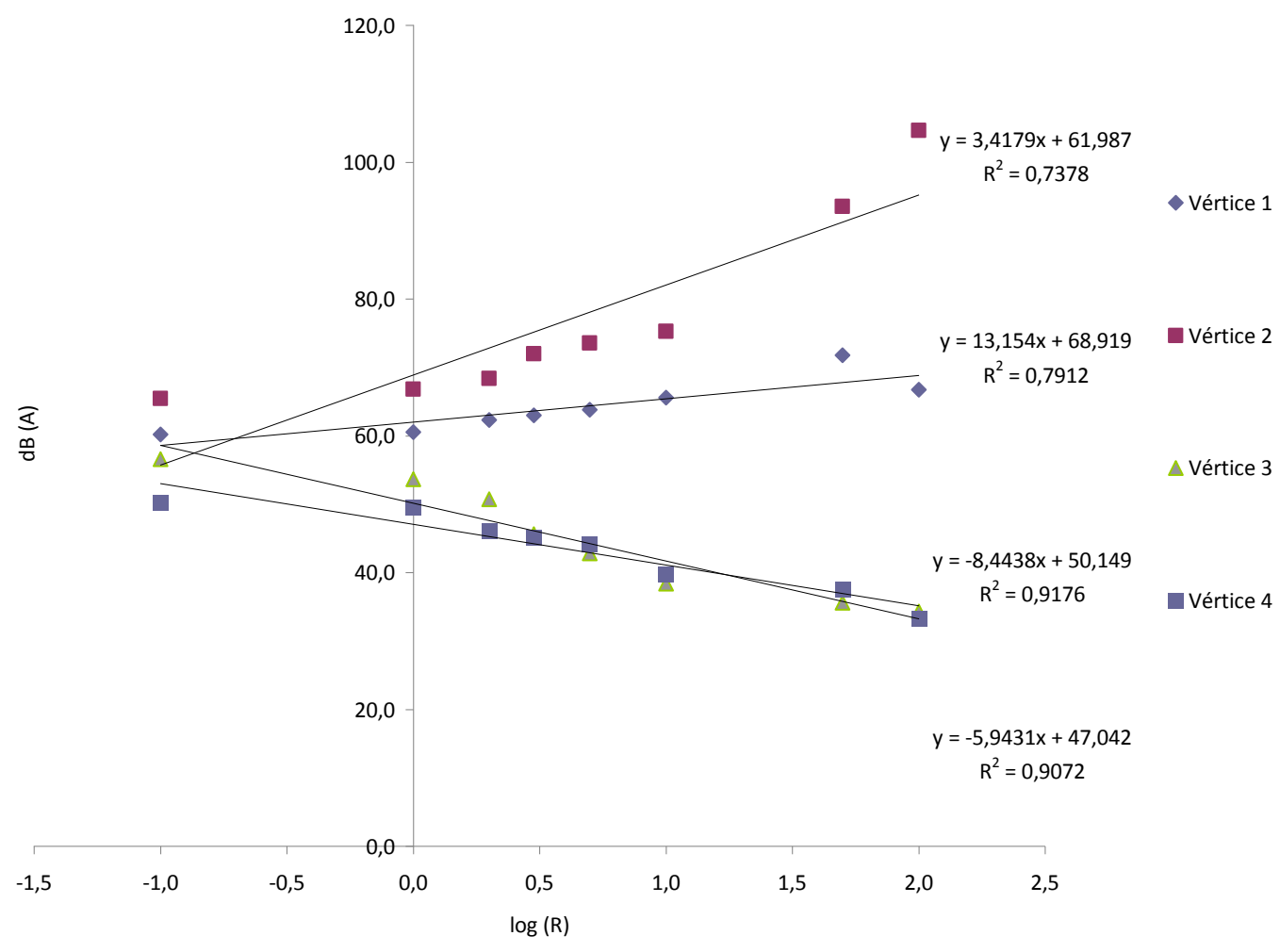

Figura 3: Curvas de atenuação dos 4 (quatro) vértices. 
Com base nessa interpretação gráfica, foi possível identificar que os vértices 3 e 4 estão aderentes a equação genérica NPS $=A-K \cdot \log (R)$. Isso significa que não existem fontes contribuintes à medida que se distancia destes vértices. No caso dos demais vértices, tal tendência não possui o mesmo comportamento, visto que há contribuições externas que vão somando e geram alterações nas previsões dos valores do parâmetro $\mathrm{K}$, inclusive conferindo a esse parâmetro valores positivos, logo, o comportamento idealizado pela Equação (4) não pode ser adotado para modelagem desses cenários. Os valores obtidos para o parâmetro $\mathrm{K}$ estão compreendidos entre 5,94 e $8.44 \mathrm{~dB}(\mathrm{~A}) \cdot \mathrm{m}^{-1}$, com coeficientes de determinação superiores a 90\%.

Uma das razões para que os valores não se ajustassem a tal modelo, que gerasse uma correlação com $\mathrm{R}^{2}$ baixos $\mathrm{e}$, por consequência, o ajuste não ficasse adequado, foram as várias fontes de ruído externas presentes ao redor da instituição, tais como: intenso fluxo de veículos e circulação de pessoas. Eniz e Garavelli (2006) identificaram cenários semelhantes, onde várias fontes externas causadoras de ruído em instituições de ensino alteram o comportamento dos índices de ruído no seu entorno, e atribuem como causas básicas o tráfego de carros de passeio e propaganda, ônibus e bicicletas.

Ademais, outro bom exemplo da influência de fontes externas de ruído pode ser verificado no vértice 2 que quanto mais se afastou da instituição, maiores são os níveis de pressão sonora determinados, provavelmente provados por efeitos fortuitos e constantes na zona de fluxo de veículos que afeta tal vértice.

Por fim, buscaram-se para uma comparação quais os parâmetros legais utilizados pelo município de Mossoró para essa aferição, porém, não foram encontradas fontes municipais de regulamentação sobre poluição sonora. Como mostrado nas Leis municipais (2010), apenas uma menção no Art. 111 da lei complementar № 47, de 16 de dezembro de 2010, que trata sobre o código de obras, posturas e edificações do município, dispõe que as edificações deverão ser projetadas de modo que as propriedades vizinhas ou logradouros públicos não sejam molestados por ruídos.

\section{CONCLUSÃO}

As atenuações naturais do ruído oriundos da instituição seguem uma relação logarítmica com a distância, para cenários de fontes unificadas e sem contaminações fortuitas, para o caso desta instituição em duas zonas verticais da posição do prédio, tendo-se ajustes aos modelos matemáticos descritos na literatura com coeficiente de determinação superiores a 90\%.

Foi possível a determinação do parâmetro $\mathrm{K}$, para a atenuação dos níveis de ruído em dois vértices do prédio, obtendo-se valores de 5,94 e $8.44 \mathrm{~dB}(\mathrm{~A}) \cdot \mathrm{m}^{-1}$ nos vértices 3 e 4 , respectivamente.

Durante as medições verificou-se a presença de fontes de ruídos externas que elevam o nível de pressão sonora do ambiente acima dos níveis da fonte objeto de análise. Este é o provável fator para explicar a razão para os vértices 1 e 2 não apresentarem atenuação do ruído conforme o modelo proposto.

Utilizando os padrões de medição da NBR 10151, com ao menos $2 \mathrm{~m}$ do limite da propriedade ou de qualquer superfície refletora, como muros, paredes etc; pode-se observar que 
as médias das leituras com $2 \mathrm{~m}$ de distância dos muros da Universidade foram todas acima do que a norma permite para a área e o horário.

Acredita-se que os principais responsáveis pelo elevado nível de ruído provocado pela universidade sejam equipamentos de ar condicionado, geradores de energia elétrica, o elevado tom de conversação dos alunos nas zonas de convivência e o trânsito de veículos dos frequentadores da instituição.

Algumas medidas poderiam ser adotadas para minimizar ou eliminar tais fontes de ruídos. Para os equipamentos de ar condicionado, estes poderiam ser enclausurados. Segundo Freitas (2013), em relação aos ruídos provenientes dos veículos poderia ser feita uma modificação com relação a superfície das pistas de tráfego de veículos, com o emprego de pavimentos de baixo ruído (PBR) e potencializando-se campanhas de conscientização sobre necessidade de manutenção do controle de emissão sonora dos veículos. Já para a conversação entre alunos uma medida que pode ser adotada é a utilização de cartazes alertando para o controle do tom de voz para um bem estar social.

Por fim, espera-se que os resultados obtidos neste mapeamento acústico e modelagem de parâmetros matemáticos possam auxiliar no planejamento da implantação de empreendimentos e edificações futuras ao redor do campus da Universidade, especialmente, pois é possível fazer a previsibilidade de certas zonas e orientar na indicação dos locais mais silenciosos e os locais mais ruidosos no seu entorno.

\section{REFERÊNCIAS BIBLIOGRÁFICAS}

1. RINALDI, Sidnei. A influência do ruído ambiental no processo de ensino/aprendizagem nos estabelecimentos de ensino público municipal na cidade de Joinville. 2005. 209 f. Dissertação (Mestrado) - Universidade de Blumenau, Blumenau, 2005. Disponível em: <http://www. academicoo.com/artigo/a-influencia-do-ruido-ambiental-no-processo-de-ensino-aprendiza gem-nos-estabelecimentos-de-ensino-publico-municipal-na-cidade-de-joinville>. Acesso em: 04 jul. 2013.

2. GIANNINI, Camila Fernanda et al. AVALIAÇÃO DO RUÍDO AMBIENTAL: MONITORAMENTO E CARACTERIZAÇÃO DO RUÍDO DE FUNDO EM MARINGÁ. Disponível em: <http://www.cesu mar.br/prppge/pesquisa/epcc2011/anais/camila_fernanda_giannini.pdf>. Acesso em: 05 jul. 2013.

3. ILDA, Itiro. Ergonomia - projeto e produção. 3a ed, São Paulo Edigard Blücher, 1995 p.

4. LACERDA, Adriana Bender Moreira De et al. Ambiente Urbano e Percepção da Poluição Sonora. Disponível em: <http://www.scielo.br/pdf/asoc/v8n2/28606.pdf>. Acesso em: 01 jul. 2013.

5. ARAÚJO, Geralda Walkiria de; DINIZ, Isabela Nogueira Araújo; GOMES JUNIOR, Weber Moreira. Determinação dos níveis de ruído em diferentes locais do município de Belo Horizonte, Minas Gerais. Anais do VIII Congresso de Ecologia do Brasil, Caxambu, n., p.1-3, 23 set. 2007.

6. BRASIL, Ministério do Trabalho e Emprego. Norma de Higiene Ocupacional - NHO 01 Avaliação da exposição ocupacional ao ruído, FUNDACENTRO, 2001. 
7. SILVA, Heloisa Maria Machado e. URBANIZAÇÃO, AUMENTO DE RUÍDO E PROBLEMAS DE VOZ: a interferência de ruídos produzidos em espaços abertos na produção vocal de professores. 2009. 133 f. Dissertação (Mestrado) - Universidade da Amazônia, Belém, 2009.

8. ZANNIN, Paulo Henrique Trombetta et al. Incômodo causado pelo ruído urbano à população de Curitiba, PR. Disponível em: <http://www.scielosp.org/pdf/rsp/v36n4/11773.pdf>. Acesso em: 01 jul. 2013.

9. BARROS, C. J. O. Análise espacial do controle da poluição sonora em Belo Horizonte. In:ENCONTRO DA SOCIEDADE BRASILEIRA DE ACÚSTICA, 19, 2000, Belo Horizonte. Anais. Belo Horizonte: SOBRAC, 2000. p. 380-385.

10. NASCIMENTO, Ludimila Souza. A influência do ruído ambiental no desempenho de escolares nos testes de padrão total de frequência e padrão total de duração. Disponível em: <http://www.scielosp.org/pdf/rsp/v36n4/11773.pdf>. Acesso em: 01 jul. 2013.

11. FÉ, Gardênia Maria de Moura. Ruído no processo de comunicação em uma instituição de ensino superior. 2009. 58 f. Dissertação (Mestrado) - Universidade de Brasília, Brasília,

12. NAGEM, Míriam Pompeu. Mapeamento e análise do ruído ambiental: diretrizes e metodologia. 2004. 119 f. Dissertação (Mestrado) - Universidade Estadual De Campinas, Campinas, 2004. Disponível em: <http://www.educadores.diaadia.pr.gov.br/arquivos/File/ 2010/artigos_teses/Ciencias/Dissertacoes/map_analise_ruido_amb.pdf>. Acesso em: 05 jul. 2013.

13. SALIBA, T. M. Curso Básico de Segurança e Higiene Ocupacional. 4. ed. São Paulo: LTR, 2011.

14. ANDRADE, Stella Maris Melazzi. METOdOLOGIA PARA AVALIAÇÃO DE IMPACTO AMBIENTAL SONORO DA CONSTRUÇÃO CIVIL NO MEIO URBANO. 2004. 253 f. Dissertação (Doutorado) Universidade Federal Do Rio De Janeiro, Rio de Janeiro, 2004.

15. DA SILVA, E. L.; MENEZES, E. M. Metodologia da pesquisa e elaboração de dissertação. 4. ed. Florianópolis: UFSC, 2005. 138p.

16. ABNT-ASSOCIAÇÃO BRASILEIRA DE NORMAS TÉCNICAS. Acústica - Avaliação do ruído em áreas habitadas, visando o conforto da comunidade - Procedimento. Disponível em: $<$ http:// www.semace.ce.gov.br/wp-content/uploads/2012/01/Avalia\%C3\%A7\%C3\%A3o+do+Ru\%C3 \%ADdo+em+\%C3\%81reas+Habitadas.pdf>. Acesso em: 01 jul. 2013.

17. ENIZ, Alexandre O.; GARAVELLI, Sergio L. A contaminação acústica de ambientes escolares devido ao ruído urbano no Distrito Federal, Brasil. HOLOS Environment, v.6, n. 2, p137-150. 2006.

18. LEIS MUNICIPAIS (Comp.). Lei Complementar de Mossoró/RN, no 47/2010 de 16/12/2010. Disponível em: <http://leismunicipais.com.br/a/rn/m/mossoro/lei-complementar/2010/4/ 47/lei-complementar-n-47-2010-dispoe-sobre-o-codigo-de-obras-posturas-e-edificacoes-domunicipio-de-mossoro-2010-12-16.html?wordkeytxt=ru\%EDdos>. Acesso em: 04 jul. 2013.

19. FREITAS, Elisabete; PAULOPEREIRA. DEFINIÇÃO E CARACTERÍSTICAS DE SUPERFÍCIES DE BAIXO RUÍDO. Disponível em: <http://www.crp.pt/docs/A45S145-32_Art_T4_7CRP_2013 .pdf>. Acesso em: 04 jul. 2013. 